\title{
BIOPOLÍTICA E EDUCAÇÃO: OS IMPACTOS DA PANDEMIA DE COVID-19 NAS ESCOLAS PÚBLICAS
}

\begin{abstract}
Alexandre de Jesus Pereira
Doutorando em Desenvolvimento Local do Centro Universitário Augusto Motta (UNISUAM), Rio de Janeiro, RJ, Brasil ajsemed@bol.com.br

Fábio Narduchi Doutorando em Educação em Ciências e Saúde da Universidade Federal do Rio de Janeiro (UFRJ), Rio de Janeiro, RJ, Brasil fabionarduchi@uol.com.br

\section{Maria Geralda de Miranda}

Docente e Pesquisadora do Programa de Pós-graduação em Desenvolvimento Local do Centro Universitário Augusto Motta (UNISUAM), Rio de Janeiro, RJ, Brasil mgeraldamiranda@gmail.com
\end{abstract}

\section{RESUMO}

O impacto causado pela pandemia do coronavírus vem impondo drásticas mudanças na rotina da população mundial. Diversas áreas foram atingidas por essas ações, entre elas, a Educação. Logo após a Organização Mundial da Saúde (OMS) declarar pandemia de coronavírus, o Ministério da Educação passou a definir critérios para a prevenção ao contágio da COVID-19 nas escolas. O desafio fundamental da educação brasileira passou a ser a adequação ao novo cenário imposto pela pandemia. Uma das medidas tomadas foi a inclusão da educação a distância - EAD - nas escolas como alternativa à interrupção das atividades presenciais. Esse dispositivo emerge para que os alunos possam cumprir a carga horária mínima exigida de horas-aula. Desse modo, o presente artigo trata de dois temas que vêm preocupando os dirigentes de educação de todo o país, são eles, o fechamento das escolas devido à pandemia de COVID-19 e a proposta de reorganização do calendário letivo dos alunos por meio do ensino a distância. O presente estudo consiste em uma pesquisa bibliográfica e documental, com material disponibilizado pela Internet no período de março a abril de 2020. Adotamos uma abordagem quali-quantitativa de natureza exploratória e descritiva.

Palavras-chave: Educação. Pandemia. Biopolítica.

\section{BIOPOLITICS AND EDUCATION: THE IMPACTS OF THE COVID-19 PANDEMIC ON PUBLIC SCHOOLS}

\begin{abstract}
The impact caused by the coronavirus pandemic has been imposing drastic changes in the routine of the world population. Several areas were affected by these actions, including education. Shortly after the
\end{abstract}


World Health Organization (WHO) declared a coronavirus pandemic, the Ministry of Education began to define criteria for preventing the contagion of COVID-19 in schools. The fundamental challenge of Brazilian education became to adapt to the new scenario imposed by the pandemic. One of the measures taken was the inclusion of distance education in schools as an alternative to interrupting classroom activities. This device emerges so that students can meet the required minimum number of hours of classes. Thus, this article deals with two themes that have been worrying education leaders across the country, namely, the closure of schools due to the pandemic imposed by COVID-19 and the proposal to reorganize the students' academic calendar through the distance learning. The present study consists of a bibliographic and documentary research, with material made available on the Internet from March to April 2020. We adopted an exploratory and descriptive qualitative and quantitative approach.

Keywords: Education. Pandemic. Biopolitics. 
BIOPOLÍTICA E EDUCAÇÃO: OS IMPACTOS

DA PANDEMIA DE COVID-19 NAS ESCOLAS PÚBLICAS
Alexandre de Jesus Pereira

Fábio Narduchi

Maria Geralda de Miranda

\section{INTRODUÇÃO}

Desde o final do ano de $2019^{24}$, o mundo tomou conhecimento do aparecimento de um novo vírus corona, a partir do comunicado feito pelas autoridades chinesas à Organização Mundial da Saúde (OMS), que imediatamente classificou o novo vírus como perigoso às populações por seu potencial de contaminação e letalidade. A OMS declarou, em 30 de janeiro de 2020, que o surto da doença causado pelo novo coronavírus (COVID-19) constitui uma Emergência de Saúde Pública de Importância Internacional - o mais alto nível de alerta da Organização, conforme previsto no Regulamento Sanitário Internacional.

Em 11 de março de 2020, a COVID-19 foi caracterizada pela OMS como uma pandemia. Esse cenário vem desafiando autoridades de várias áreas que passaram a adotar dispositivos biopolíticos de controle com o objetivo de regular a vida dos indivíduos.

O impacto causado pela pandemia do novo coronavírus vem impondo drásticas modificações na rotina da população mundial. Diversas áreas foram atingidas por essas mudanças, entre elas, a educação. Logo após a OMS declarar pandemia de coronavírus, o Ministério da Educação passou a definir critérios para a prevenção ao contágio da COVID-19 nas escolas. Desse modo, o desafio fundamental da educação brasileira tem sido se readequar ao cenário para que os estudantes não sejam prejudicados com a pandemia.

Este artigo está dividido em quatro momentos. Na primeira parte, analisamos o impacto do coronavírus no cenário global. Em seguida, discorremos sobre o conceito de biopolítica, a fim de compreendermos melhor as atuais práticas e políticas que estão surgindo, na escola, para prevenção da COVID-19. Depois, tratamos de dois temas que vêm preocupando os dirigentes de educação de todo o país, são eles, o fechamento das escolas devido à pandemia imposta pelo novo coronavírus e a proposta de reorganização do calendário letivo dos alunos por meio do ensino a distância. Por fim, apresentamos algumas medidas que a Secretaria de Estado de Educação do Rio de Janeiro (SEEDUC) vem tomando frente à pandemia de Covid-19.

\section{IMPACTO DO CORONAVÍRUS NO CENÁRIO GLOBAL}

\footnotetext{
${ }^{24}$ Em 31 de dezembro de 2019, a Organização Mundial da Saúde (OMS) foi alertada sobre vários casos de pneumonia na cidade de Wuhan, província de Hubei, na República Popular da China. Tratava-se de uma nova cepa (tipo) de coronavírus que não havia sido identificada antes em seres humanos. Uma semana depois, em 7 de janeiro de 2020 , as autoridades chinesas confirmaram que haviam identificado um novo tipo de coronavírus. Os coronavírus estão por toda a parte. Eles são a segunda principal causa de resfriado comum (após rinovírus) e, até as últimas décadas, raramente causavam doenças mais graves em humanos do que o resfriado comum (ORGANIZAÇÃO PAN-AMERICA DE SAÚDE, 2020).
} 
Em 31 de dezembro de 2019, a Organização Mundial da Saúde (OMS) foi alertada sobre vários casos de pneumonia na cidade de Wuhan, província de Hubei, na República Popular da China. Tratava-se de um novo tipo de coronavírus que não havia sido identificado antes em seres humanos. Uma semana depois, em 7 de janeiro de 2020, as autoridades chinesas confirmaram que haviam identificado um novo tipo de coronavírus, conforme dados divulgados pela Organização Pan-Americana da Saúde (ORGANIZAÇÃO PAN-AMERICA DE SAÚDE, 2020).

De acordo com a Organização Mundial da Saúde (OMS), o coronavírus, causador da doença Covid-1925, alcançou o patamar de pandemia no dia 11 de março de 2020. Originada na China, a pandemia chegou ao Brasil no mês de fevereiro com o primeiro caso registrado no dia 26 de fevereiro.

No início do mês de março de 2020, a Organização das Nações Unidas para a Educação, Ciência e Cultura (UNESCO) realizou a primeira contagem global da situação educacional impactada pela pandemia de Covid-19, como é chamada oficialmente. No relatório, foram registrados quase 300 milhões de alunos afetados em 22 países de três continentes pelo fechamento de escolas devido à expansão do vírus (ENTENDA..., 2020). A crise de saúde ${ }^{26}$ gerada pelo novo coronavírus trouxe grandes preocupações entre as nações de todos os continentes, alterando profundamente as relações políticas e econômicas em escala global ${ }^{27}$.

Para que esse fenômeno seja bem compreendido, é necessário inicialmente explanar dois importantes conceitos; são eles: pandemia e globalização. O termo "pandemia" se refere à

\footnotetext{
${ }^{25}$ Os coronavírus (CoV) são uma grande família viral, conhecidos desde meados dos anos 1960, que causam infecções respiratórias em seres humanos e em animais. Geralmente, infecções por coronavírus causam doenças respiratórias leves a moderada, semelhantes a um resfriado comum. A maioria das pessoas se infecta com os coronavírus comuns ao longo da vida. Todos os coronavírus são transmitidos de pessoa a pessoa, incluindo os SARS-CoV, porém sem transmissão sustentada. Alguns coronavírus podem causar síndromes respiratórias graves, como a síndrome respiratória aguda grave que ficou conhecida pela sigla SARS da síndrome em inglês Severe Acute Respiratory Syndrome. SARS é causada pelo coronavírus associado à SARS (SARS-CoV), sendo os primeiros relatos na China em 2002. O SARS-CoV se disseminou rapidamente para mais de doze países na América do Norte, América do Sul, Europa e Ásia. Os coronavírus são a segunda principal causa do resfriado comum (após rinovírus) e, até as últimas décadas, raramente causavam doenças mais graves em humanos do que o resfriado comum. Há sete tipos de coronavírus humanos (HCoVs) conhecidos, entre eles, o SARS-COV (que causa síndrome respiratória aguda grave), o MERS-COV (síndrome respiratória do Oriente Médio) e o SARS-CoV-2 (vírus que causa a doença COVID-19). A Organização Mundial de Saúde a descreve como COVID-19, uma doença infecto-respiratória semelhante à gripe. Por ser um vírus novo, a taxa de infecção é alta, pois não há imunidade por adoecimento prévio ou proteção por vacina (ORGANIZAÇÃO PAN-AMERICA DE SAÚDE, 2020).

${ }^{26} \mathrm{O}$ conceito de saúde utilizado aqui é o da OMS, que se refere ao cuidado da saúde de uma população como um todo (ORGANIZAÇÃO MUNDIAL DA SAÚDE, 2011). Os dois principais objetivos dos esforços para promover a saúde pública são: manter as pessoas saudáveis e prevenir doenças (ORGANIZAÇÃO MUNDIAL DA SAÚDE, 2011).

${ }^{27}$ Disponível em: https://nacoesunidas.org/. Acesso em: 10 abr. 2020.
} 
BIOPOLÍTICA E EDUCAÇÃO: OS IMPACTOS

DA PANDEMIA DE COVID-19 NAS ESCOLAS PÚBLICAS
Alexandre de Jesus Pereira

Fábio Narduchi

Maria Geralda de Miranda

distribuição geográfica de uma doença e não à sua gravidade. Uma pandemia é uma doença infecciosa, transmissível e mortal que se espalha por vários países e regiões do mundo. Ela se difere de uma epidemia devido às suas maiores proporções. Ao longo da história, podemos encontrar vários exemplos de pandemias. São exemplos de casos de pandemia a AIDS, a tuberculose e os recentes surtos de gripe aviária, em 2005, e de gripe suína, em 2009 (FRANÇA, c2006-2020). O que difere casos antigos dos casos contemporâneos é a maior velocidade de propagação das doenças, devido ao aumento das possibilidades de contágio, sendo a globalização a responsável por essas mudanças (FRENK; GÓMEZ-DANTÉS, 2007).

A globalização ${ }^{28}$ é um fenômeno cuja origem está na ascensão do capitalismo no que tange ao comércio e às finanças, em um contexto de revoluções no transporte e nas telecomunicações (VEIGA, 2006). Para Guattari (2013a), o termo globalização se aplica ao neoliberalismo vigente, que o autor nomeia de Capitalismo Mundial Integrado (CMI), por entender que ele não tem fronteiras regionais ou nacionais desde a década de 80. Para o autor, trata-se do capitalismo contemporâneo (neoliberal), que não se baseia exclusivamente na exploração do trabalho, mas, sobretudo, na exploração da vida (GUATTARI, 2013a, 2013b).

O capitalismo contemporâneo é mundial e integrado, porque potencialmente colonizou o conjunto do planeta, porque atualmente vive em simbiose com países que historicamente pareciam ter escapado dele (os países do bloco soviético, a China) e porque tende a fazer com que nenhuma atividade humana, nenhum setor de produção fique fora do seu controle (GUATTARI, 2013a, p. 211).

Brown, Cueto, Fee (2016, p. 625) associam a globalização

A crescente importância de atores para além de agências e organizações governamentais e intergovernamentais - por exemplo, a mídia, fundações influentes internacionalmente, corporações transnacionais. Logicamente, os termos 'internacional', 'intergovernamental' e 'global' não são mutuamente excludentes e, de fato, podem ser entendidos como complementares. (BROWN; CUETO; FEE, 2016, p. 625).

Os autores afirmam que a globalização traz como principal desafio pensar a saúde das populações. A Organização Mundial da Saúde (OMS) é uma agência intergovernamental que desempenha funções internacionais com o objetivo de melhorar a saúde global. A agência trata da "coordenação, planejamento estratégico e liderança de iniciativas de saúde global" (BROWN; CUETO; FEE, 2016, p. 623), sendo uma importante organização na adoção de dispositivos

\footnotetext{
${ }^{28}$ A globalização tem seu marco político no final da década de 1980, durante o Consenso de Washington, do qual faziam parte instituições financeiras de ajuda internacional americanas, como: o Banco Mundial, o Fundo Monetário Internacional (FMI) e o Banco Interamericano de Desenvolvimento (BID) (FIORI, 2007).
} 
BIOPOLÍTICA E EDUCAÇÃO: OS IMPACTOS

DA PANDEMIA DE COVID-19 NAS ESCOLAS PÚBLICAS
Alexandre de Jesus Pereira

Fábio Narduchi

Maria Geralda de Miranda

biopolíticos de controle, de regulação dos corpos, voltados, em seu caso específico, para a saúde da população.

\section{PANDEMIA E BIOPOLÍTICA}

A realidade gerada pela pandemia do novo Coronavírus nos contribui para o resgate do conceito foucaultiano de biopolítica, ou seja, uma tecnologia que traz mecanismos de intervenção com a intenção de governar a população e os fenômenos produzidos pela vida na coletividade. A biopolítica emerge como uma forma de poder que se exerce sobre os fenômenos da vida, o nascimento, a fecundidade, a velhice, as enfermidades e a morte: "são fenômenos coletivos, que só aparecem com seus efeitos econômicos e políticos, que só se tornam pertinentes no nível da massa" (FOUCAULT, 2008, p. 293).

O surgimento da pandemia faz emergir uma série de mecanismos que atuam para combater a doença, regulando assim a vida da população. Tais medidas apresentam-se como processos que buscam fazer previsões, estimativas, probabilidades, medições (FOUCAULT, 2004b, 2008).

Foucault (2008) aponta três campos onde a biopolítica intervém: a higiene pública, o meio urbano e os mecanismos de segurança. Esses domínios permitem intervir sobre tais fenômenos e assim estabelecer mecanismos reguladores dessa população. Trata-se de formas de controle e prevenção da doença. Nesse cenário, criaram-se medidas preventivas de higiene que se disseminaram por meio de campanhas pelo Brasil sobre prevenção do novo coronavírus. É nesse contexto de prevenção que a pandemia ganha maior visibilidade no conjunto das práticas sociais, ou melhor, de doenças que se propagariam nas escolas.

Para ilustrar o que constituiria o campo de atuação da biopolítica, Foucault (2008) dá o exemplo do controle de epidemias. O filósofo analisa práticas denominadas por ele como mecanismos de segurança, que também se apresentam como mecanismos de normalização, ocasião para uma reconfiguração, em larga escala, das tecnologias do poder. Para o autor, os dispositivos de segurança são ferramentas de governo que permitem encarar a população como um foco de intervenção. O "objetivo final" dos dispositivos de segurança será a "população" (FOUCAULT, 2008, 2004a).

Os dispositivos de segurança trabalham, fabricam, organizam, acondicionam um meio. [...] O meio será então o âmbito no qual se dá a circulação. É um conjunto de dados naturais [...] e um conjunto de dados artificiais, aglomeração de indivíduos, aglomeração 
de casas, etc. [...] Através do meio aponta-se, por tanto, a esse fenômeno de circulação das causas e dos efeitos. E o meio aparece por último como um campo de intervenção onde, em vez de afetar aos indivíduos como um conjunto de sujeitos de direito capazes de ações voluntárias [...], tratar-se-á de afetar, precisamente, a uma população (FOUCAULT, 2007, p. 41; 2004a, p. 22-23).

Nosso autor considera que "[...] o problema da cidade era essencial e fundamentalmente um problema de circulação" (FOUCAULT, 2008, p. 29). Ao tratar dos dispositivos de segurança, o autor cita como exemplo o modelo da quarentena que era um método de controle utilizado, na Europa, durante o século XVII, ligado ao problema da peste. Esse modelo visava "maximizar a saúde, a longevidade, a força dos indivíduos, tratava-se no fundo de produzir uma população sadia" (FOUCAULT, 2008, p. 58). A partição rigorosa de todo o espaço da cidade, não descuidando de nenhum lugar, a fim de que os corpos (das pessoas) não transgredissem os limites fixados para sua mobilidade que, no caso, estava fixado pelo perímetro da habitação de cada indivíduo.

\footnotetext{
Na biopolítica, o agenciamento do espaço corresponderá ao problema da organização de um "meio" que permita a circulação das coisas e das pessoas. A normalização, por sua vez, irá se referir aos procedimentos de regulação que atuam sobre os processos gerais da vida. E o corpo a ser singularizado como objeto e sujeito dos mecanismos de poder é o corpo coletivo das populações (FONSECA, 2011, p. 242).
}

A administração da cidade, através de seus funcionários, era encarregada da vigilância e da obediência a essas regras. Assim, esses funcionários eram os únicos aptos a se movimentarem entre os espaços esquadrinhados da cidade. O relatório constante da situação que havia, no interior de cada habitação, era feito pelo fiscal a seu superior hierárquico. Os habitantes eram submetidos a uma contagem, de modo a verificar quantos permaneciam vivos, quantos estavam doentes e quantos estavam mortos. As casas desabitadas eram, até mesmo, desapropriadas e "procedimentos de purificação acompanhavam a evacuação das casas contaminadas, e se seguiam de fumigação". Todo o espaço, portanto, era objeto de controle, devendo as patologias ser relatadas às autoridades centrais e todo movimento, regulamentado - os mínimos detalhes da vida cotidiana sob vigília (DREYFUS; RABINOW, 1995, p. 208).

O autor ressalta que existem quatro noções importantes nos discursos políticobiológicos: caso, risco, perigo e crise. A construção dessas quatro noções tornou possível medir os casos de sucessos e de fracassos dessa política de saúde, surgindo assim a noção de doença, não mais como algo a eliminar, mas como distribuição de casos dentro de determinada 
BIOPOLÍTICA E EDUCAÇÃO: OS IMPACTOS

DA PANDEMIA DE COVID-19 NAS ESCOLAS PÚBLICAS
Alexandre de Jesus Pereira

Fábio Narduchi

Maria Geralda de Miranda

população, no interior da qual se poderá verificar os riscos e perigos a que cada subgrupo estará sujeito em razão da idade, do clima, da localidade, etc. (FOUCAULT, 2008).

A ação governamental surge para o gerenciamento dessas situações, bem como intervenções, no sentido de normalizar esse acontecimento. Assim, os dispositivos de segurança pretendem ser reguladores, agindo sobre as questões epidêmicas, reduzindo os danos possíveis de serem causados por eles. Na sociedade de segurança, a preocupação está voltada para o conjunto de indivíduos e não para cada caso isolado; não se trata de sanar todos os problemas sociais, mas de reduzir os danos causados por eles e deixá-los em um nível aceitável.

Assim, a biopolítica opera um controle sobre os fenômenos coletivos utilizando estratégias e mecanismos regulamentadores que buscarão encontrar um equilíbrio para a produção de uma população saudável. Trata-se de "levar em conta a vida, os processos biológicos do homem-espécie e de assegurar sobre eles não uma disciplina, mas uma regulamentação" (FOUCAULT, 2008, p. 294).

Essas medidas são importantes para que haja controle na identificação do número de indivíduos acometidos pela doença em um determinado espaço do território, a sua faixa etária, o índice de mortalidade entre os doentes, quais regiões são mais afetadas, ou seja, a partir desse conjunto de informações, é possível fazer um levantamento estatístico para saber qual é o risco de morbidade a que um indivíduo estará submetido ao ser exposto, considerando a sua idade, o lugar em que mora, a faixa etária, etc. A biopolítica opera por meio de cálculos que equacionem riscos e perigos da maneira mais eficiente possível (FOUCAULT, 2008).

\section{A COVID-19 E SUAS IMPLICAÇÕES NA EDUCAÇÃO}

No dia 11 de março de 2020, a Organização Mundial de Saúde (OMS) declarou que a disseminação de COVID-19 se caracterizava com uma pandemia global (ORGANIZAÇÃO PANAMERICA DE SAÚDE, 2020). A partir daí, ela traçou algumas estratégias biopolíticas com o objetivo de prevenir, combater e controlar os altos níveis de coronavírus no mundo. O Ministério da Saúde editou a Portaria no 188 declarando Emergência em Saúde Pública de Importância Nacional, em razão da infecção humana causada pelo novo coronavírus (BRASIL, 2020d). 
BIOPOLÍTICA E EDUCAÇÃO: OS IMPACTOS

DA PANDEMIA DE COVID-19 NAS ESCOLAS PÚBLICAS
Alexandre de Jesus Pereira

Fábio Narduchi

Maria Geralda de Miranda

O Ministério da Educação ${ }^{29}$ também precisou definir critérios para a prevenção ao contágio da COVID-19 nas escolas. A partir do mês de março de 2020, os estados da federação brasileira passaram a adotar diversas medidas públicas, entre elas a suspensão das atividades escolares. O objetivo era evitar aglomerações, que poderiam contribuir para a disseminação do novo vírus. Temos aí não somente a OMS, mas também o MEC como instâncias e campos de atuação da biopolítica.

No Rio de Janeiro, o governo paralisou as aulas nas redes pública e privada. Dados retirados do site da Secretaria Municipal de Educação (SME) mostram que há 1.540 unidades de ensino público com um total de 626.778 alunos (RIO DE JANEIRO, 2020a), num território marcado por diferenças econômicas, sociais e culturais.

O quadro abaixo apresenta o total de unidades que estavam em funcionamento em março de 2020, antes da pandemia, com o quantitativo de alunos, bem como por tipo de atendimento, o que nos dá uma dimensão da problemática que se apresentava às autoridades, neste caso, municipais, logo após o fechamento das escolas.

Quadro 1 - Total de unidades de ensino público municipal em funcionamento e total de alunos

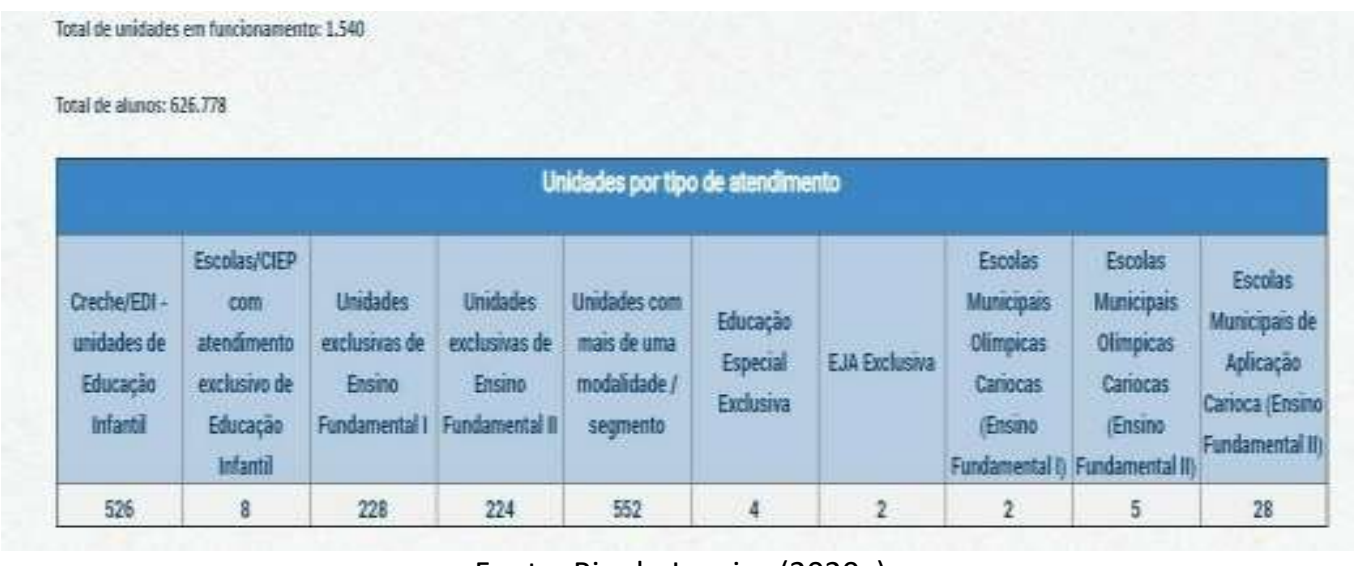

Fonte: Rio de Janeiro (2020a).

Com o fechamento das escolas, as unidades passaram a adotar o ensino a distância (EAD) a partir do dia 30 de março de 2020. A adoção das atividades não presenciais, apoiadas pelo uso dos recursos oferecidos pelas Tecnologias de Informação e Comunicação (TIC), constituiu-se, assim, num caminho para minimizar as perdas causadas, no campo da educação, pelo isolamento social. Dessa forma, as TICS surgem como uma alternativa para evitar que os estudantes sofram prejuízos no processo de ensino-aprendizagem.

${ }^{29}$ Vide: http://blog.mds.gov.br/redesuas/. Acesso em: 11 abr. 2020. 
BIOPOLÍTICA E EDUCAÇÃO: OS IMPACTOS

DA PANDEMIA DE COVID-19 NAS ESCOLAS PÚBLICAS
Alexandre de Jesus Pereira

Fábio Narduchi

Maria Geralda de Miranda

Visando contornar as perdas acadêmicas e pedagógicas, no ensino superior, o Ministério da Educação (BRASIL, 2020a) publicou, no dia 17 de março de 2020, a Portaria no 343, dispondo sobre a substituição das disciplinas presenciais, em andamento, por aulas que utilizem meios e tecnologias de informação e comunicação enquanto durar a situação de pandemia do Novo Coronavírus - COVID-19.

A Lei de Diretrizes e Bases da Educação Nacional (LDB) já previa a possibilidade de ensino a distância em casos emergenciais. A partir deste entendimento, os Conselhos de Educação de vários estados se manifestaram para regulamentar e amparar as escolas que optaram por continuar suas atividades pedagógicas de maneira remota (BRASIL, 1996).

Em 19 de março de 2020, o MEC alterou o citado documento, pela publicação da Portaria nำ345/2020. Em seu art. 1ำ, esta última Portaria dispõe o seguinte:

Fica autorizada, em caráter excepcional, a substituição das disciplinas presenciais, em andamento, por aulas que utilizem meios e tecnologias de informação e comunicação, por instituição de educação superior integrante do sistema federal de ensino, de que trata 0 art. 20 do Decreto no 9.235, de 15 de dezembro de 2017. (BRASIL, 2020b).

A ação tem caráter excepcional e valerá enquanto durar a situação de emergência de saúde pública por conta do atual coronavírus. Como nada foi mencionado em relação à Educação Básica, em nota de esclarecimento (BRASIL, 2020c) publicada em 18 de março, o Conselho Nacional de Educação afirmou que caberia às autoridades dos sistemas de ensino federal, estaduais, municipais e distritais autorizar a realização de atividades a distância nos seguintes níveis e modalidades de ensino: Fundamental, Médio, Educação Profissional Técnica de nível Médio, Educação de Jovens e Adultos (EJA) e Educação Especial.

Com isso, os Conselhos Estaduais de Educação (CEE) começaram a se posicionar criando deliberações, resoluções e pareceres sobre o tema, permitindo a adoção de atividades escolares a distância, na Educação Básica, enquanto durar o período de excepcionalidade causado pela propagação da COVID-19. A secretaria estadual do Rio de Janeiro se posicionou favoravelmente por meio da Deliberação CEE/RJ n 376, de 23 de março de 2020. Tal deliberação autorizou a todas as Instituições integrantes do Sistema Estadual de Ensino do Estado do Rio de Janeiro a "promoverem atividades não presenciais, em caráter de excepcionalidade e temporalidade, enquanto permanecerem as medidas de isolamento previstas pelas autoridades estaduais na prevenção e combate ao Coronavírus - COVID-19". (RIO DE JANEIRO, 2020b). 
BIOPOLÍTICA E EDUCAÇÃO: OS IMPACTOS

DA PANDEMIA DE COVID-19 NAS ESCOLAS PÚBLICAS
Alexandre de Jesus Pereira

Fábio Narduchi

Maria Geralda de Miranda

Os artigos 2ㅇ e 5ㅇ da Deliberação CEE-RJ no 376/20 (RIO DE JANEIRO, 2020b) estabelecem os requisitos para a execução do regime especial domiciliar, cujo cumprimento precisa ser efetivamente demonstrado tanto pela rede pública estadual quanto pelas unidades escolares da rede privada que pretendam fazer uso da autorização normativa, por meio da elaboração conjunta e apresentação formal às comunidades escolares do plano de ação pedagógica referido pela norma, dentre outros requisitos.

Para além do cumprimento do art. 2ㅇ da Deliberação CEE-RJ no 376/2020, a Secretaria de Estado de Educação (SEEDUC) e as escolas privadas submetidas à sua fiscalização deverão comprovar a efetiva existência de condições materiais e tecnológicas colocadas à disposição tanto do corpo docente quanto do corpo discente, de modo a assegurar a universalidade, a equidade e a qualidade do atendimento escolar. Tal demonstração mostra-se imperiosa, sobretudo na rede pública, tendo em vista a notória situação de exclusão digital experimentada por parte significativa do alunado e dos professores da rede estadual.

A Resolução CNE/CEB n. 03/2018, em seu artigo 17, § 13, dispõe que:

As atividades realizadas pelos estudantes, consideradas partes da carga horária do ensino médio, podem ser atividades com intencionalidade pedagógica orientadas pelos docentes, podendo ser realizadas na forma presencial - mediada ou não por tecnologia - ou a distância. (BRASIL, 2018).

O MEC conceitua a EAD (Ensino a Distância) como uma forma de "ensino que possibilita a autoaprendizagem, com a mediação de recursos didáticos [...] organizados, apresentados em diferentes suportes de informação, utilizados isoladamente ou combinados, e veiculados pelos diversos meios de comunicação" (BRASIL, 1998, p. 1). Costa (2017, p. 6), define a EAD como:

Uma modalidade de educação planejada por instituições e que utiliza diversas tecnologias de comunicação. É uma forma de ensino-aprendizagem mediada por Tecnologias da Informação e Comunicação (TICS) que permitem que o professor e o estudante estejam em ambientes físicos diferentes. (COSTA, 2017, p. 61).

De acordo com Barbosa (2012), as TICs ${ }^{30}$ têm um papel fundamental na EAD, elas trouxeram novo sentido à Educação, por meio de trocas sociais na proposta pedagógica. A utilização das Tecnologias da Informação e Comunicação (TIC) vem trazendo transformações

\footnotetext{
${ }^{30}$ A denominação TIC, Tecnologias de Informação e Comunicação, diz respeito aos procedimentos, métodos e equipamentos usados para processar a informação e comunicá-la aos interessados. As TICs agilizaram o conteúdo da comunicação, através da digitalização e da comunicação em redes (Internet) para a captação, transmissão e distribuição das informações, que podem assumir a forma de texto, imagem estática, vídeo ou som (MAIA, 2003).
} 
significativas em todos os setores profissionais e, no âmbito educacional, vem com a finalidade de maximizar e dinamizar o processo de ensino/aprendizagem (BOTTENTUIT JR; COUTO, 2012), gerando uma nova cultura e um novo modelo de sociedade (KENSKI, 2012).

Estudos (LEVY; 1999; POZO, 2008; VIEIRA, 2011; MENDONÇA et al., 2013) apontam questões relevantes sobre a transformação metodológica na Educação da sociedade atual, diante das novas tecnologias de informação e comunicação (TICS), especialmente, na modalidade de educação a distância (EAD).

\section{MEDIDAS DA SECRETARIA DE ESTADO DE EDUCAÇÃO DO RIO DE JANEIRO FRENTE À PANDEMIA}

A Secretaria de Estado de Educação do Rio de Janeiro (SEEDUC) ${ }^{31}$, em função da paralisação das aulas em consequência da pandemia de coronavírus, vem tomando uma série de medidas, para que o processo de ensino-aprendizagem dos alunos não seja prejudicado. Uma delas foi disponibilizar uma plataforma virtual do Google For Education para as aulas dessa rede pública. O Google Classroom ${ }^{32}$, também conhecido como Google Sala de Aula, é uma plataforma pertencente ao tradicional site de buscas, para que alunos da rede pública estadual possam ter aulas on-line, a fim de compensar a perda de horário letivo ${ }^{33}$.

A plataforma possui três seções principais: o Mural, que permite que professores e alunos enviem mensagens e dúvidas; as Atividades, que reúnem lições, tarefas e provas; e a aba Pessoas, que mostra todos os estudantes e docentes que têm acesso. O Tutorial Google Classroom, para se criar uma sala de aula online, foi posto à disposição de alunos e de professores nas redes sociais da Secretaria de Estado de Educação (SEEDUC). Para acessar os conteúdos, será necessária a criação de uma conta Google (PLATONOW, 2020). Cada aluno do Ensino Médio, na

\footnotetext{
${ }^{31}$ A Secretaria Municipal de Educação (SME) é o órgão da Prefeitura do Rio de Janeiro responsável por elaborar a política educacional do município do Rio de Janeiro, coordenar a sua implantação e avaliar os resultados, com o objetivo de assegurar a excelência na Educação Infantil e no Ensino Fundamental público, é o objetivo primeiro da Secretaria Municipal de Educação. Disponível em: http://www.rio.ri.gov.br/web/sme. Acesso em: 13 abr. 2020.

32 O Google Classroom é um sistema de gerenciamento de conteúdo para escolas que procuram simplificar a criação, a distribuição e a avaliação de trabalhos. Ele é um recurso do Google Apps para a área de educação e foi lançado para o público em agosto de 2014. Cada aluno do Ensino Médio, na rede pública do RJ, recebe uma conta de e-mail com primeiro nome, número da matrícula e sufixo @aluno.educa.rj.gov.br . O tutorial para os alunos, professores e diretores já foi divulgado nas redes sociais da SEEDUC (www.facebook.com/seeducRJ/ e no Instagram @SeeducRJ), além de ser distribuído por Whatsapp para toda a rede.

${ }^{33}$ A Secretaria de Estado de Educação (SEEDUC) e o Google For Education disponibiliza o acesso para alunos pelo link: https://sites.google.com/educa.rj.gov.br/aluno.
} 
BIOPOLÍTICA E EDUCAÇÃO: OS IMPACTOS

DA PANDEMIA DE COVID-19 NAS ESCOLAS PÚBLICAS
Alexandre de Jesus Pereira

Fábio Narduchi

Maria Geralda de Miranda

rede pública do RJ, recebe uma conta de e-mail com primeiro nome, número da matrícula e sufixo @aluno.educa.rj.gov.br.

Os conteúdos das aulas estão sendo incluídos nas salas virtuais, ao longo da semana. A experiência, no entanto, pode ser problemática, pois, apesar de o caput do art. 70, que abre o Capítulo II do $\mathrm{MCl}$ e que trata dos direitos e garantias dos usuários da internet, afirmar que o acesso à internet é universal e essencial ao exercício da cidadania, nem todos tem acesso à internet no Brasil (BAPTISTA, 2012), sendo que, em sua ausência, não há a possibilidade de interação entre aluno e professor (VIEIRA, 2011; FERNANDES; FERNANDES, 2011; BARBOSA, 2012; MENDONÇA et al., 2013).

A Pesquisa TIC Domicílio34 (CETIC, 2018), realizada, em 2018, com 23,5 mil pessoas - em diferentes regiões do Brasil - apontou que mais de 30\% das casas não têm acesso à internet, em geral as mais pobres. Os dados indicaram que há, no país, 126,9 milhões de usuários, ou seja, $70 \%$ da população. O número mostra crescimento em relação à edição 2017 , quando $67 \%$ navegavam. O estudo revela ainda que a desigualdade social continua sendo fator determinante para o acesso. Enquanto o porcentual de pessoas da classe A com acesso foi de $92 \%$, nas classes D e E, o índice fica em 48\%. O preço das conexões de banda larga é um dos fatores que leva parte dos usuários das classes mais desfavorecida a não ter acesso.

Pensando nisso, a Secretaria de Estado de Educação do Estado do Rio de Janeiro passou a imprimir e entregar o material didático para os estudantes que não têm acesso à internet. Além disso, a SEEDUC se prontificou a debater com a comunidade escolar para verificar a possibilidade e disponibilidade de abrir pontualmente algumas unidades de ensino, para que alunos e docentes que não possuem computador e aparelhos de telefone celular para realização das atividades a distância tenham acesso aos laboratórios e equipamentos dos colégios. Livros e materiais didáticos das bibliotecas também poderão ser utilizados para ministrar os conteúdos das disciplinas.

Uma outra resolução importante foi a medida provisória que foi publicada no dia 01 de abril de 2020 na edição extra do Diário Oficial da União. A medida promove ajustes no calendário

\footnotetext{
${ }^{34}$ É necessário ressaltar que a TIC Domicílio é, seguramente, um dos principais indicadores do estágio de inclusão digital no Brasil, apresentando um papel importante no norteamento das políticas públicas de inclusão digital no Brasil. A pesquisa realizada pelo Centro de Estudos sobre as Tecnologias da Informação e da Comunicação (Cetic.br), em 2018, apontou que a maior parte os alunos das escolas públicas ainda não tem acesso à internet; isso impediria que as medidas tecnológicas se tornassem efetivas. A pesquisa TIC Domicílios é realizada anualmente, desde 2005 , com o objetivo de mapear o acesso à infraestrutura TIC nos domicílios urbanos e rurais do país e as formas de uso destas tecnologias por indivíduos (CETIC, 2018).
} 
BIOPOLÍTICA E EDUCAÇÃO: OS IMPACTOS

DA PANDEMIA DE COVID-19 NAS ESCOLAS PÚBLICAS
Alexandre de Jesus Pereira

Fábio Narduchi

Maria Geralda de Miranda

escolar de 2020 (BRASIL, 2020). A medida provisória no 934, que "estabelece normas excepcionais sobre o ano letivo da educação básica e do ensino superior decorrentes das medidas para enfrentamento da situação de emergência de saúde pública de que trata a Lei no 13.979, de 6 de fevereiro de 2020" (BRASIL, 2020e, p. 1).

A Medida Provisória dispensa as escolas de Educação Básica e as Instituições de Ensino Superior de cumprirem o mínimo de 200 dias letivos anuais. No Ensino Básico ${ }^{35}$, a medida vale desde que seja mantida a carga horária mínima de 800 horas de aula por ano. A contagem pode ser feita com recuperação das aulas em turno integral, após a crise, ou considerar o tempo de aulas virtuais ministradas durante o fechamento das escolas em razão da pandemia do novo coronavírus (BRASIL, 2020e). Essa medida é restrita ao ano letivo afetado pelo enfrentamento da situação de emergência na saúde pública.

\section{CONSIDERAÇÕES FINAIS}

O cenário de enfrentamento à pandemia vem exigindo medidas biopolíticas por parte do Estado, na área da educação, em função da pandemia de coronavírus. As ações que estão sendo tomadas para gerir a educação vêm proporcionando uma regulação social, "de modo que pensar qualquer mudança no âmbito da escola implica pensar como as coisas estão se passando no âmbito da sociedade" (VEIGA-NETO, 2003, p. 109). Algumas dessas medidas têm sido tomadas no sentido de minimizar o prejuízo em relação à aprendizagem dos conteúdos curriculares.

A escola, como instituição social, tem um papel fundamental diante desta pandemia. Ela deve oferecer opções que ajudem os alunos a compreenderem o momento que eles estão vivendo. A necessidade de distanciamento social, para conter a disseminação do novo coronavírus na escola, traz, em seu bojo, a busca por alternativas para que o calendário escolar não seja prejudicado.

Nesse sentido, o ensino a distância surge como uma alternativa para evitar que os estudantes sofram prejuízos em consequência da pandemia. Os componentes curriculares passam a ser trabalhados de forma remota, sendo que essa medida segue uma tendência

\footnotetext{
${ }^{35}$ A Lei de Diretrizes e Bases da Educação Nacional dispõe, em seu artigo 24o, inciso primeiro, que a carga horária mínima anual da Educação Básica, nos níveis Fundamental e Médio, será de oitocentas horas, distribuídas por um mínimo de duzentos dias de efetivo trabalho escolar, excluído o tempo reservado aos exames finais, quando houver (BRASIL, 1996).
} 
presente em diversos países que se viram frente à necessidade de suspender as aulas por causa do novo coronavírus. Lembrando que o uso de tecnologias a distância, no contexto das ações para promover o ensino-aprendizagem em tempo de isolamento, não tem como objetivo substituir o ensino presencial. Ele tem somente a intenção de suprir uma necessidade do momento, evitando que os estudantes percam o ano letivo.

\section{REFERÊNCIAS}

BAPTISTA, Cláudia Fróis de Figueiredo. Jornalismo e alternativas mediáticas na era da Internet: A profissão perante o novo paradigma do acesso livre do cidadão à divulgação de informação na Internet. 2012. Mestrado (Mestrado em Cultura e Comunicação) - Faculdade de Letras, Universidade de Lisboa, Lisboa, 2012. Área de Literaturas, Artes e Culturas.

BARBOSA, Cláudia Maria Arôso Mendes. A aprendizagem mediada por TIC: interação e cognição em perspectiva. Revista Brasileira de Aprendizagem Aberta e a Distância, São Paulo, v. 11, p. 83-100, set. 2012.

BOTTENTUIT JR, J.B.; COUTO, F. A. O Uso das Tecnologias de Informação e Comunicação no Ensino Fundamental II: um estudo com alunos e professores de uma escola em São Luís - MA. Revista Educação Online, v. 6, n.2 mai/ago. 2012.

BRASIL. Ministério da Educação. Conselho Nacional de Educação. Câmara de Educação Básica. Resolução no 3, de 21 de novembro de 2018. Atualiza as Diretrizes Curriculares Nacionais para o Ensino Médio. Diário Oficial da União: seção 1, Brasília, DF, ano 224, p. 21, 22 nov. 2018.

BRASIL. Ministério da Educação. Gabinete do Ministro. Portaria no 343, de 17 de março de 2020. Dispõe sobre a substituição das aulas presenciais por aulas em meios digitais enquanto durar a situação de pandemia do Novo Coronavírus - COVID-19. Diário Oficial da União: seção 1, Brasília, DF, ano 53, p. 39, 18 mar. 2020a.

BRASIL. Ministério da Educação. Gabinete do Ministro. Portaria no 345, de 19 de março de 2020. Portaria no 345, de 19 de março de 2020, que altera a Portaria MEC no 343, de 17 de março de 2020. Diário Oficial da União: seção 1, Brasília, DF, extra, n. 54-D, p. 1, 19 mar. 2020b.

BRASIL. Ministério da Educação. Conselho Nacional de Educação. Nota de Esclarecimento. Diário Oficial da União, Brasília, DF, 18 mar. 2020c. Disponível em: http://consed.org.br/media/download/5e78b3190caee.pdf. Acesso em: 20 mar. 2020.

BRASIL. Ministério da Saúde. Gabinete do Ministro. Portaria no 188, de 03 de fevereiro de 2020. Declara Emergência em Saúde Pública de importância Nacional (ESPIN) em decorrência da Infecção Humana pelo novo Coronavírus (2019-nCoV). Diário Oficial da União: seção 1, Brasília, DF, 04 fev. 2020d.

BRASIL. Medida Provisória no 934, de 10 de abril de 2020. Estabelece normas excepcionais sobre o ano letivo da educação básica e do ensino superior decorrentes das medidas para 
enfrentamento da situação de emergência de saúde pública de que trata a Lei no 13.979, de 6 de fevereiro de 2020. Diário Oficial da União: seção 1, Brasília, DF, p. 1, 1 abr. 2020. Disponível em: http://www.in.gov.br/en/web/dou/-/medida-provisoria-n-934-de-1-de-abril-de-2020250710591. Acesso em: 11 abr. 2020.

BRASIL. Lei no 9.394, de 20 de dezembro de 1996. Estabelece diretrizes e bases da educação nacional. Diário Oficial da União, Brasília, DF, 23 dez. 1996. Disponível em: http://www.planalto.gov.br/ccivil_03/leis/I9394.htm. Acesso em: 11 abr. 2020.

BRASIL. Decreto n. 2.494, de 10 de fevereiro de 1998. Regulamenta o Art. 80 da LDB (Lei n.은 9.394/96). Diário Oficial da União, Brasília, DF, 11 fev. 1998.

BROWN, Theodore M.; CUETO, Marcos; FEE, Elizabeth. A transição de saúde pública 'internacional' para 'global' e a Organização Mundial da Saúde. História, Ciência, Saúde: Manguinhos, Rio de Janeiro, v .13, n.3, p. 623-647, jul./set. 2006.

CETIC. Centro de Estudos sobre as Tecnologias da Informação e da Comunicação. TIC Domicílios 2018: pesquisa sobre o Uso das Tecnologias de Informação e Comunicação no Brasil. São Paulo, 20 jun. 2018. Disponível em: http://www.cetic.br/. Acesso em: 02 abr. 2020.

COSTA, Adriano Ribeiro da. A educação à distância no Brasil: concepções, histórico e bases legais. Revista Eletrônica do Centro Universitário do Rio São Francisco, Paulo Afonso, n. 12, p. 59-74, 2017. Disponível em:

https://www.unirios.edu.br/revistarios/media/revistas/2017/12/a_educacao_a_distancia_no_b rasil_concepcoes_historico_e_bases_legais.pdf. Acesso em: 29 maio 2020.

DREYFUS, Hubert L.; RABINOW, Paul. Michel Foucault, uma trajetória filosófica: para além do estruturalismo e da hermenêutica. Tradução de Vera Porto Carrero. Rio de Janeiro: Forense Universitária, 1995.

RIO DE JANEIRO. Secretaria Municipal de Educação. Educação em números. Rio de Janeiro: SME, 2020a. Disponível em: http://www.rio.rj.gov.br/web/sme/educacao-em-numeros. Acesso em: 15 abr. 2020.

ENTENDA como o novo coronavírus impacta a educação em todo o mundo: relatório da Unesco registrou quase 300 milhões de estudantes afetados pela pandemia do novo coronavírus, em 22 países. Empresa Brasil de Comunicação, Brasília, DF, 19 mar. 2020. Disponível em: https://radios.ebc.com.br/revista-brasil/2020/03/impactos-educacionais-por-causa-do-covid19. Acesso em: 10 abr. 2020.

FERNANDES, Ana Paula Lima Marques; FERNANDES, Ronaldo Ribeiro. A importância a importância das TICs como recurso didático no ensino da Matemática Financeira. In: SIMPÓSIO DE EXCELÊNCIA EM GESTÃO E TECNOLOGIA, 9., 2012, Resende, RJ. Anais [...]. Resende, RJ: AEDB, 2012. p.1-10.

FIORI, J. L. Neoliberalismo e políticas públicas. In: FIORI, J. L. Os moedeiros falsos. Petrópolis: Vozes, 2007. 
FONSECA, Márcio Alves da. Entre a vida governada e o governo de si. In: ALBUQUERQUE JÚNIOR, Durval Muniz de; VEIGA-NETO, Alfredo; SOUZA FILHO, Alípio (org.). Cartografias de Foucault. Belo Horizonte: Autêntica, 2011. p. 241-251.

FOUCAULT, M. Em defesa da sociedade. São Paulo: Martins Fonte, 2008.

FOUCAULT, M. O Nascimento da biopolítica: curso dado no Collège de France (1978-1979). São Paulo: Martins Fonte, 2004a.

FOUCAULT, M. Segurança, território e população: cursos doCollege de France (1977-1978). São Paulo: Martins Fonte, 2004b.

FRANÇA, N. Endemia, epidemia e pandemia. In: InfoEscola: navegando e aprendendo. [S. I.], c2006-2020. Disponível em: http://www.infoescola.com/doencas/endemia-epidemia-epandemia/. Acesso em: 13 abr. 2020.

FRENK, J.; GÓMEZ-DANTÉS, O. Globalização e Saúde: desafios para os sistemas de saúde em um mundo interdependente. [S. I.: s. n.], 2006-2007. Disponível em: http://files.bvs.br/upload/S/1555-8746/2007/vn4/a65-77-1.pdf. Acesso em: 04 abr. 2020.

GUATTARI, Félix. O Capitalismo Mundial Integrado e a Revolução Molecular. In: ROLNIK, Suely (Org.). Revolução Molecular. Pulsações políticas do desejo. Brasiliense, São Paulo, $2013 a$.

GUATTARI, Félix. Revolução Molecular: pulsações políticas do desejo. São Paulo, SP: Editora Brasiliense, 2013b.

KENSKI, V. M. Educação e tecnologias: o novo ritmo da informação. 8. ed. Campinas, SP: Papirus, 2012.

LEVY, Pierre. Cibercultura. Rio de Janeiro: Editora 34, 1999.

MAIA, Marta C. O uso da tecnologia de informação para a educação a distância no ensino superior. 2003. Tese (Doutorado em Administração de Empresas) - Escola de Administração de Empresas de São Paulo, Fundação Getulio Vargas, São Paulo, 2009. Área de concentração: Produção e Sistemas de Informação.

MENDONÇA, José Ricardo Costa de et al. Competências Eletrônicas de Professores para Educação a Distância no Ensino Superior no Brasil: discussão e proposição de modelo de análise. Pernambuco: Universidade Federal de Pernambuco, 2013.

ORGANIZAÇÃO MUNDIAL DA SAÚDE. WHO Recommendations for Prevention and Treatment of Pre-eclampsia and Eclampsia: Summary of Recommendations. Geneva: World Health Organization, 2011.

ORGANIZAÇÃO PAN-AMERICA DE SAÚDE. Organização Mundial de Saúde. COVID-19 (doença causada pelo novo coronavírus). Folha Informativa, 6 abr. 2020. Disponível em: 
BIOPOLÍTICA E EDUCAÇÃO: OS IMPACTOS

DA PANDEMIA DE COVID-19 NAS ESCOLAS PÚBLICAS
Alexandre de Jesus Pereira

Fábio Narduchi

Maria Geralda de Miranda

https://www.paho.org/bra/index.php?option=com_content\&view=article\&id=6101:covid19\&It e mid=875. Acesso em: 4 abr. 2020.

POZO, J.I. A sociedade da aprendizagem e o desafio de converter informação em conhecimento. In: SALGADO, Maria. Tecnologias na Educação: ensinando e aprendendo com as TIC: guia do cursista. Brasília, DF: Ministério da Educação, Secretária de Educação à Distância, 2008.

PLATONOW, Vladimir. Escolas estaduais começam estudos online no Rio de Janeiro: Plataforma utilizada será viabilizada pelo Google For Education. Agência Brasil, Rio de Janeiro, 27 de mar. de 2020.

RIO DE JANEIRO (Estado). Deliberação CEE N³76, DE 23 DE MARÇO DE 2020. Orienta as Instituições integrantes do Sistema Estadual de Ensino do estado do Rio de Janeiro sobre o desenvolvimento das atividades escolares não presenciais, em caráter de excepcionalidade e temporalidade, enquanto permanecerem as medidas de isolamento previstas pelas autoridades estaduais na prevenção e combate ao Coronavírus - COVID-19. Diário Oficial do Estado do Rio de Janeiro, Rio de Janeiro, 25 mar. 2020b, p. 15-16. Disponível em:

http://www.cee.rj.gov.br/deliberacoes/D_2020-376.pdf. Acesso em: 10 mar. 2020.

VEIGA, J. Desenvolvimento sustentável: o desafio do século XXI. Rio de Janeiro: Garamond, p. 33, 2006.

VEIGA-NETO, A. Pensar a escola como uma instituição que pelo menos garanta a manutenção das conquistas fundamentais da modernidade. In: COSTA, M. V. (Org.). A escola tem futuro?. Rio de Janeiro: DP\&A, 2003. p. 103-123.

VIEIRA, Rosângela Souza. O Papel das tecnologias da informação e comunicação informação e comunicação na educação a distância: um estudo sobre a percepção do professor/tutor.

Revista Brasileira de Aprendizagem Aberta e a Distância, São Paulo, v. 10, p. 68-70, 2011.

Recebido em 18/02/2020

Aceito em 28/02/2020 